\title{
Variation in leaf biomass and fruit output of Juniperus indica along an elevation gradient in north-central Nepal
}

\begin{abstract}
A. Chapagain ${ }^{1 * 3}$, R. P. Chaudhary ${ }^{2}$ and S. K. Ghimire ${ }^{3}$
Biomass and reproductive output are important functional traits that influence aspects of plant performance. Measurements of these attributes by harvesting plant parts are often destructive and impractical. Therefore, non-destructive methods, based on allometric relationships, have been recommended for measuring plant biomass and reproductive output, particularly in the ecosystems where plant harvesting is not very practical or feasible. Here, we assessed the variation in the traits related to vegetative and reproductive performance (including plant height, trunk diameter, canopy area, leaf biomass and number of fruits set) among populations of Juniperus indica distributed along an elevation gradient in Manang district of the north-central Nepal, and finally determined the allometric relationships addressing the leaf biomass and the fruit output. The distribution range of $J$. indica was divided into lower- $(3,350$ $3,580 \mathrm{~m})$, mid- $(3,650-3,880 \mathrm{~m})$ and higher- $(3,950-4,250 \mathrm{~m})$ elevation classes where we made 54 sample plots of $10 \mathrm{~m} \times 10 \mathrm{~m}$ size. In each plot, we recorded the number of individuals of $\mathrm{J}$. indica classifying into seedling, juvenile and mature classes, and measured their vegetative traits and fruit output. Trunk diameter, leaf dry-weight and fruits set parameters spatially varied within the same elevation class. The individuals at the lower-elevation were larger in vegetative size with larger- trunk, height and canopy area, and produced higher leaf biomass and greater number of fruits as compared to those produced by the individuals situated at the mid- and higher-elevations. The regression analysis showed the strongest relationship between the canopy area and the leaf biomass. Thus, the use of outer canopy dimension is found to be the best option for estimation of leaf biomass of $J$. indica using non-destructive method..
\end{abstract}

Key words: Fruit output, leaf biomass, Manang, non-destructive method

$\mathrm{P}$ lant biomass and reproductive output are important functional traits that determine plant growth, aspects of individual performance and competitive ability. There are two methods available for estimating plant biomass- i) destructive method and ii) non-destructive method. The destructive method, also known as the harvest method is the most commonly used method for measuring plant biomass and reproductive output. It is the most direct and accurate method, and involves plant harvesting in the known area, and measuring the fresh or oven-dried weight of the different plant parts for biomass estimation (Tackenberg, 2007; Vashum and Jayakumar, 2012). Measurements of these attributes by harvesting plant parts are often destructive, and time-as well as resource-

consuming, and require a large number of samples, which is impractical for rare and threatened species. Therefore, non-destructive methods, based on allometric relationships, have been recommended for measuring plant biomass in such ecosystems where plant harvesting is not very practical or feasible (Tackenberg, 2007; Vashum and Jayakumar, 2012). Non-destructive measurements of plant allometric attributes (e.g., height, canopy dimensions and stem diameter) have long been used to estimate plant biomass (Mason and Hutchings, 1967; Peek, 1970; Ludwig et al., 1975) and reproductive output (Haymes and Fox, 2012; Otárola et al., 2013). Recent interests in quantifying ecosystem carbon stocks, and potential uses of bio-energy have shown the need of implementing non-destructive methods to

\footnotetext{
${ }^{1}$ Federation of Community Forestry Users Nepal (FECOFUN), Duwakot, Bhaktapur, Nepal.

*E-mail: arjun1chapagain@gmail.com

${ }^{2}$ Research Centre for Applied Science and Technology, Tribhuvan University, Kirtipur, Kathmandu, Nepal

${ }^{3}$ Central Department of Botany, Tribhuvan University, Kirtipur, Kathmandu, Nepal
} 
estimate total above ground biomass (Ansley et $a l ., 2012$ ). Studies indicate that canopy area and/ or stem diameter can provide the best regression fit for above ground biomass prediction in several tree species including Juniperus (Mason and Hutchings, 1967; Ansley et al., 2012).

Juniperus indica is an important component of sub-alpine forest of Manang district, northcentral Nepal (Ghimire et al., 2008a). Juniperus forest in the Nepal Himalayas is under threat due to high anthropogenic pressure (e.g., destructive practices, such as over-harvesting of leaves for incense and slash-burning to harvest its wood) as well as harsh climatic conditions. Studies carried out in other parts of the world have shown that the principal ecological problems in junipers are related to low production of viable seeds (Juan et al., 2003; Otto et al., 2010). Juan et al. (2003) assessed viability in $J$. oxycedrus which showed difficulties in seed germination because of harsh cold climate. In some species of Juniperus, low reproductive success is due to low amount of pollen that reaches female individuals resulting in less number of fruits set (Juan et al., 2003).

Most of the works on Himalayan junipers are confined to essential oil variation in leaf (e.g., Adams and Chaudhary, 1996; Adams et al.,1998), taxonomic determination (e.g., Adams et al., 2009), and ethnobotany (e.g., Bhattarai et $a l ., 2006)$. Ethnobotanical study of junipers ( $J$. indica, J. squamata and J. communis) in Manang by Bhattarai et al. (2006) revealed that the local community and traditional Tibetan traditional practitioner had been using almost all parts for different purposes. Fruits, leaves, stem and barks of Juniperus spp. are used in traditional medicine to cure kidney, skin and lymph disorders, fever, cough and cold, sores, wounds, and paralysis of limbs (Bhattarai et al., 2006; Ghimire et al., 2008b); leaves are also burnt for incense by followers of Buddhism. The plant is also used as fencing material and for carving different household items (Bhattarai et al., 2006). Dried leaves are sold locally for incense, and essential oil obtained from steam distillation of fresh leaves is traded internationally for its use in medicines and cosmetics (Ghimire et al., 2008b; Gurung, 2010). Leaves are harvested throughout the year while fruits during July to August. These all activities put heavy pressure on Juniperus stands in the forest ecosystem.
In this study, we sampled $J$. indica along an elevation gradient in Manang district situated in the north-central Nepal, and examined the relationship among the traits associated with vegetative and reproductive performances. We assessed the variations in the traits related to vegetative and reproductive performance (including plant height, trunk diameter, canopy area, leaf biomass and number of fruits set) among the populations distributed along the three elevation gradients. Finally, we determined the relationship among the allometric traits with leaf biomass and fruit output.

\section{Materials and methods}

\section{Study area}

$J$. indica is native to high-altitude Himalaya, occurring from the northern Indus Valley in Kashmir to western Yunnan in China and it occurs throughout Nepal at elevations ranging from 3,300 $\mathrm{m}$ to $4,500 \mathrm{~m}$ above sea level (Press et al., 2000). The plant is found on open and rocky alpine slopes in drier areas; sometimes forming forests at lower elevations. The plant occurs as dwarf woody-shrub at higher elevations exceeding 4,200 $\mathrm{m}$ and as tree growing at lower elevations of range 3,300-4,000 $\mathrm{m}$ above sea level (Ghimire et al., 2008b). The leaves are dark grey-green, dimorphic, mature plants having mostly scale-like leaves which are decussate or sometimes in whorls of 3, closely appressed, 1-3 $\mathrm{mm}$ long; while young plants have mostly needlelike leaves, which are borne in whorls of 3 and are 5-8 $\mathrm{mm}$ long. Needle-like leaves are also found on shaded shoots of adult plants. The plant is dioecious with male (pollen) and female (seed) cones on separate plants. The pollen cones are sub-globose or ovoid, 2-3 mm long; seed cones are ovoid, berry-like, 6-10 mm long, glossy black when ripe, and contain a single seed. The cones are seen in April to May, and mature in October to December. The seeds are mostly dispersed by birds, which eat the cones (Ghimire et al., 2008b).

\section{Study area}

The study area is located in Manang district of the north-central part of Nepal (Fig. 1). It lies within the broad U-shaped Trans-Himalayan valley dissected by the Marshyangdi River, and is extended up to the north of the Annapurna Mountain Range (up to 7,000 m asl). The northern 
part of the Manang Valley, therefore receives very low annual monsoonal precipitation of 450 $\mathrm{mm}$, whereas the precipitation at southern region (Chame, Manang, at 2,680 m asl) remains to be over 1,000 mm (Miehe et al., 2001; Baniya et al., 2009). Similarly, the mean annual temperature remains $6.2^{\circ}$ Celsius in the northern TransHimalayan valley while $11.0^{\circ}$ Celsius in the southern region in Manang district. The moisture is found to be decreasing from east to west in the Upper Manang Valley, and the south-facing slopes are much drier than those facing north (Bhattarai et al., 2004; Ghimire et al., 2008a).

Vegetation in the Manang Valley at elevations above $3,000 \mathrm{~m}$ supports the luxuriant stands of Pinus wallichiana, Betula utilis and Abies spectabilis on the north-facing slopes, and some patches of $P$. Wallichiana on the dry south-facing slopes (Baniya et al., 2009). J. indica and Rosa sericea with other shrubs are dominant on the dry south-facing slopes. At the lower elevations, the vegetation mainly comprises $J$. squamata, Lonicera obovata and Caragana gerardiana.

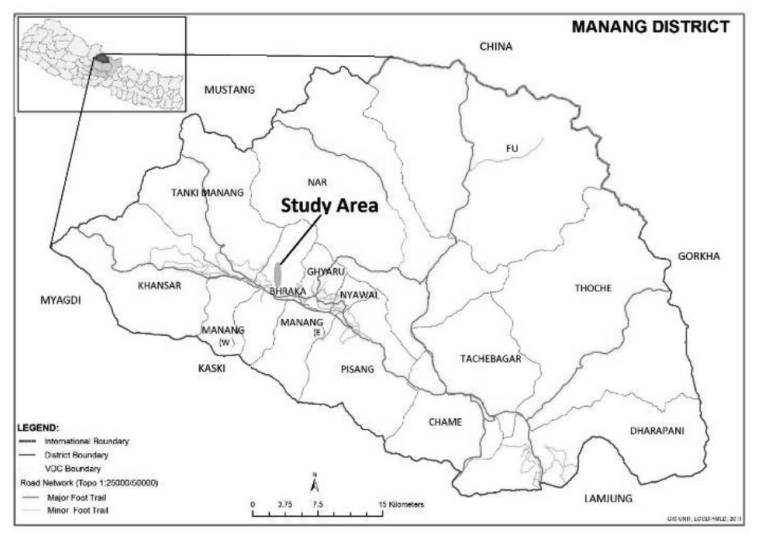

Fig. 1: Map of the study area

\section{Methods}

The sampling of $J$. indica population was carried out in September 2011 during fruiting season in the north-eastern part of the Manang Valley. A systematic sampling approach was used. The study was started from Bhraka Village $(3,350 \mathrm{~m}$ asl) almost at the bottom of the valley to the Ice Lake $(4,250 \mathrm{~m}$ asl). The whole of the distribution range was divided into lower- $(3,350-3,580 \mathrm{~m})$, mid- $(3,650-3,880 \mathrm{~m})$ and higher- $(3,950-4,250$ m) elevation classes so as to cover the wider range of distribution of $J$. indica, heterogeneous environmental conditions and diverse vegetation types. In each elevation class, three horizontal transects were laid at 75-100 $\mathrm{m}$ elevation intervals. In each transect, six plots of size $10 \mathrm{~m} \times$ $10 \mathrm{~m}$ were sampled at 50-100 m length intervals, totaling 54 plots from all transects and elevation classes. Each plot $\left(100 \mathrm{~m}^{2}\right)$ was further divided into 4 subplots of $5 \mathrm{~m} \times 5 \mathrm{~m}$ size.

In each subplot, individuals of $J$. indica of different size (maturity) classes were recorded separately. The size classes were recognized corresponding to their growth stages following Schemske et al. (1994). The size classes were broadly defined according to the plant height or trunk diameter as seedlings (height $<0.1 \mathrm{~m}$ and trunk diameter $<1$ $\mathrm{cm}$ ), juveniles (height $0.1-1.0 \mathrm{~m}$, trunk diameter $<1 \mathrm{~cm}$ ) and mature (height usually $>1 \mathrm{~m}$, trunk diameter $>1 \mathrm{~cm}$ and also bearing reproductive structure). The mature individuals were recorded for their height (ground level to the top of the canopy), trunk diameter, canopy area and number of fruits. The trunk diameters of mature $>1-3 \mathrm{~m}$ tall individuals were measured at $25 \mathrm{~cm}$ aboveground, whereas the trunk diameters of mature $>3 \mathrm{~m}$ tall individuals were measured at $137 \mathrm{~cm}$ above ground. The crown cover was directly measured in terms of the canopy area occupied by each adult individual using Measuring Tape. In each plot, a mature individual was randomly selected, and its leaves were collected within an area of $0.0625 \mathrm{~m}^{2}$ by randomly placing a small quadrat $(0.25 \mathrm{~m} \times 0.25 \mathrm{~m})$ on the crown surface. All the leaves within the selected quadrats were collected from the crown base to the tip across the vertical profile. The leaves were packed in paper bags, and fresh weight was taken with the help of a Spring Balance (error of \pm 2.5 gm).In the field, all the leaf samples, collected from each plot, were packed in cotton bags, and dried in shade. After returning to the laboratory, the samples were oven dried at $600^{\circ} \mathrm{C}$ for 72 hours, and dry weight was recorded with the help of a Digital Weighing Machine (error $\pm 1.5 \mathrm{gm}$ ). We could collect the samples from only 46 plots due to the absence of mature individuals in the rest 8 plots. The number of fruits per tree was counted only from one mature individual present within each sub-plot. We could measure the number of fruits from only 90 plants, one each from 90 subplots as the mature individuals were completely absent in the remaining sub-plots as in the 8 plots. The latitude, longitude and altitude of each plot were recorded with the help of Global Positioning System (GPS) device. The aspect and slope of each plot were recorded with the help of Compass and Clinometer, respectively. 
The variations in the vegetative and reproductive traits among the three elevation classes was tested using one-way ANOVA. The relationships between the vegetative and reproductive traits were analyzed by calculating Pearson Correlation Coefficients. The traits exhibiting statistically significant correlations were further analyzed through linear regression analysis to evaluate the strength of relationships and derive allometric equations. Particularly, we focused on significant allometric traits to predict the leaf biomass (vegetative trait) and the number of fruits (reproductive trait). To meet the statistical assumptions of normality and homogeneity of variance while fitting linear regression, the trunk diameter, the plant height, the leaf dry weight and the number of fruits were $\log$ transformed, and the canopy area was square-root transformed. All the statistical analyses were performed using the SPSS 17.0 Software.

\section{Results and discussion}

Variation in vegetative and reproductive traits

The Mean, Standard Error (SE) and the range values of the vegetative and the reproductive traits of $J$. indica recorded in the Ice Lake Area of the Upper Manang Valley are given in Table 1. Most of the individuals were of moderate to small size with the height, trunk diameter and canopy area ranging from $0.5 \mathrm{~m}$ to $25.0 \mathrm{~m}, 0.95 \mathrm{~cm}$ to 60.48 $\mathrm{cm}$ and $0.01 \mathrm{~m}^{2}$ to $2.01 \mathrm{~m}^{2}$, respectively. The mean leaf dry weight per $0.0625 \mathrm{~m}^{2}$ canopy was found to be $0.031 \mathrm{~kg}$, ranging from $0.013 \mathrm{~kg}$ to 0.058 $\mathrm{kg}$; the mean dry leaf biomass was calculated to be $28.98 \mathrm{~kg}$ per ha. The mean number of fruits per plant ranged from 10 to 1040 (mean 202.9).

J. indica showed higher values of all its vegetative and reproductive traits at the lower-elevation than at the mid- and the higher-elevations (Fig. 2). The individuals of $J$. indica at the lower-elevation were found to be larger in size, with larger trunk, height, canopy area, and produced higher leaf biomass and greater number of fruits as compared to those from the mid- and the higher-elevations (Fig. 2).
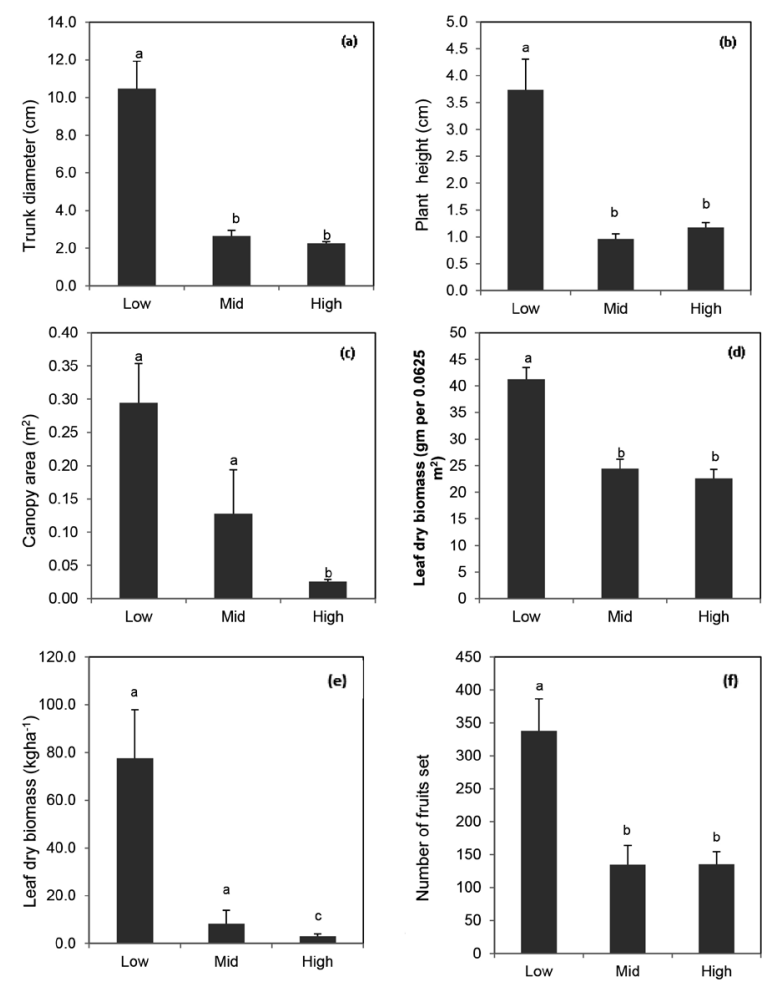

Fig. 2: Variations in (a) trunk diameter, (b) plant height, (c) canopy area, (d) leaf dry biomass (gm per $0.0625 \mathrm{~m}^{2}$ ), (e) leaf dry biomass $\left(\mathrm{kgha}^{-1}\right)$, and (f) number of fruits set of $J$. indica at the three elevation classes (low, mid and high) around the Ice Lake in the Upper Manang Valley. The means with different letters represent significant difference in the traits among the three elevation classes at $<0.05$ level of significance based on the Oneway ANOVA.

Table 1: Mean, SE and range values of the vegetative and the reproductive traits of $J$. indica recorded in the Ice Lake Area of the Upper Manang Valley

\begin{tabular}{lrrrrr}
\hline Traits & N & Mean & SE & Minimum & Maximum \\
\hline Plant height $(\mathrm{m})$ & 134 & 2.62 & 0.26 & 0.50 & 25.00 \\
Trunk diameter $(\mathrm{cm})$ & 134 & 5.82 & 0.71 & 0.95 & 60.48 \\
Canopy area $\left(\mathrm{m}^{2}\right)$ & 134 & 0.16 & 0.03 & 0.01 & 2.01 \\
Leaf dry weight $(\mathrm{g})$ per $0.0625 \mathrm{~m}^{2}$ canopy & 46 & 31.12 & 1.65 & 12.50 & 58.10 \\
Leaf dry weight $(\mathrm{g})$ per plant & 46 & 153.26 & 47.27 & 1.22 & 1801.51 \\
Leaf dry biomass $\left(\mathrm{kg} \mathrm{ha}^{-1}\right)$ & 46 & 28.98 & 8.37 & 0.18 & 202.20 \\
Number of fruits per plant & 90 & 202.90 & 21.64 & 10.00 & 1040.00 \\
\hline
\end{tabular}




\section{Correlation among the traits}

The Pearson Correlation Analysis revealed significant relationships among a numbers of traits of $J$. indica (Table 2). Significant correlations $(p=<0.01)$ were observed between the trunk diameter and the plant height $(\mathrm{r}=0.58)$, the trunk diameter and the canopy area $(\mathrm{r}=0.34)$, the trunk diameter and the leaf dry weight $(\mathrm{r}=0.54)$, the canopy area and the leaf dry weight $(r=0.93)$, the trunk diameter and the number of fruits $(\mathrm{r}=0.44)$, and the plant height and the number of fruits $(r=0.34)$.

\section{Regression analysis for statistically significant traits}

The allometric traits exhibiting statistically significant correlations with leaf dry weight and fruit production were further analyzed using simple linear regression analysis to evaluate the strength of relationships and derive allometric equations (Fig. 3). The relationship between the plant height and the leaf dry weight and between the canopy area and the number of fruits were not further analyzed as their strength of relationship was very low (Table 2). Of the three allometric measurements (trunk diameter, plant height and canopy area), the canopy area was found to be the strongest variable to explain the variability of the total leaf biomass (Fig. 3b).
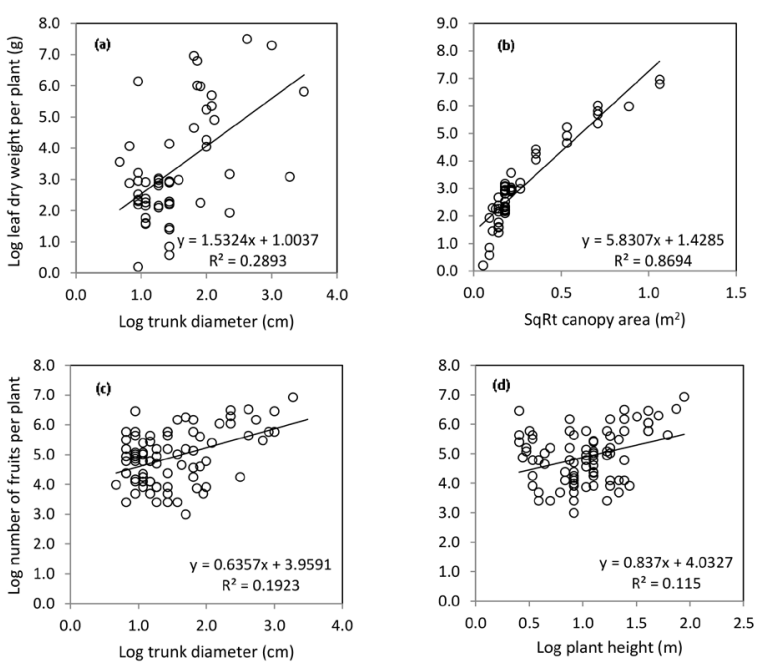

Fig. 3: Relationships between (a) the trunk diameter and the leaf dry weight, (b) the canopy area and the leaf dry weight, (c) the trunk diameter and the no. of fruits, and (d) the plant height and the no. of fruits. Fitted line based on linear regression model.

The canopy area of $J$. indica in the present study varied from $0.01 \mathrm{~m}^{-2}$ to $2.01 \mathrm{~m}^{-2}$ per tree which is far less than the findings of Ghimire and Devkota (2008) who measured the canopy area of J. indica of the Kangchenjunga Conservation Area, East Nepal to be $7.98 \pm 0.32 \mathrm{~m}^{2}$ (mean $\pm \mathrm{SE}$, range: $0.01-7.98 \mathrm{~m}^{2}$ ). This might be because of the difference in the micro-climate between the more mesic condition of the Eastern Himalaya and the xeric microclimate of the Manang Valley. Of the three allometric measurements (trunk diameter, plant height and canopy area), the canopy area was found to be the strongest variable $\left(\mathrm{r}^{2}=0.869\right)$

Table 2: The Pearson correlation coefficients among the vegetative and reproductive traits of $J$. indica

\begin{tabular}{|c|c|c|c|c|c|c|}
\hline Traits & Abbreviation & TrDiam & Ht & CanAr & DrWtPl & NoFr \\
\hline Trunk diameter & TrDiam & $\begin{array}{c}1 \\
(\mathrm{n}=131)\end{array}$ & & & & \\
\hline Plant height & $\mathrm{Ht}$ & $\begin{array}{c}0.580 * \\
(\mathrm{n}=129)\end{array}$ & $\begin{array}{c}1 \\
(\mathrm{n}=129)\end{array}$ & & & \\
\hline Canopy area & CanAr & $\begin{array}{c}0.344^{*} \\
(\mathrm{n}=124)\end{array}$ & $\begin{array}{c}-0.074 \\
(\mathrm{n}=122)\end{array}$ & $\begin{array}{c}1 \\
(\mathrm{n}=127)\end{array}$ & & \\
\hline Leaf dry weight per plant & DrWtPl & $\begin{array}{c}0.538^{*} \\
(\mathrm{n}=53)\end{array}$ & $\begin{array}{c}0.252 \\
(\mathrm{n}=52)\end{array}$ & $\begin{array}{c}0.932 * \\
(\mathrm{n}=51)\end{array}$ & $\begin{array}{c}1 \\
(\mathrm{n}=56)\end{array}$ & \\
\hline Number of fruits per plant & $\mathrm{NoFr}$ & $\begin{array}{c}0.439^{*} \\
(\mathrm{n}=87)\end{array}$ & $\begin{array}{c}0.339^{*} \\
(\mathrm{n}=87)\end{array}$ & $\begin{array}{c}0.100 \\
(\mathrm{n}=82)\end{array}$ & $\begin{array}{c}0.332 \\
(\mathrm{n}=33)\end{array}$ & $\begin{array}{c}1 \\
(\mathrm{n}=88)\end{array}$ \\
\hline
\end{tabular}

Note: Statistically significant correlations $(\mathrm{p}=<0.05)$ are denoted by asterisk $(*)$; other correlations being insignificant. 
for predicting the total leaf biomass. The Average canopy area and, thus, the mean leaf dry weight per plant tended to be high at the lower-elevation, which decreased gradually towards the mid- and the higher-elevations. Subedi (2016) also reported highest leaf biomass in J. squamata at the low elevation in the Manang Valley. Linear negative relationship between biomass and elevation has been reported for several woody plant speices (e.g., Rastetter et al., 2004). Plants growing along an elevation gradient exhibit reduction in radial and vertical growth of their stem towards higher elevations mostly caused by corresponding decline in temperature and nutrient availability, and delay in start of seasonal growth (Körner et al., 1983; Klinka et al., 1996).

Among the other allometric variables, the trunk diameter was found to be less strong for predicting total leaf biomass $\left(r^{2}=0.289\right)$. Plant height was found to be even less effective predictor of leaf biomass, which is similar to the findings of Ansley et al. (2012). The reason might be due to the suppression and release from suppression in vertical growth at different time periods and space, corresponding to light intensity, moisture and temperature. Measurements of basal trunk diameter and canopy height are difficult in bushyjuniper because of very compact canopy with a high density of under-growth stems that restrict access to the core base of the stems. Thus, the use of individual outer canopy dimensions may be the best option for non-destructively estimating leaf biomass of $J$. indica as reported in other species (Ansley et al., 2012).

None of the allometric traits considered in this study showed strong power for predicting fruit-output. Nevertheless, larger plants [with greater trunk diameter $\left(r^{2}=0.192\right)$ and height $\left.\left(r^{2}=0.115\right)\right]$ produced more fruits as compared to the smaller ones (Table 2). As the individuals at the lower elevation are generally larger in size, they produced greater number of fruits than those in the mid- and higher-elevations. The less number of fruits produced per plant in the mid- and high-elevations may also be due to the limited pollination success as reported by Juan et al.(2003) as a result of the wider spatial distance between the male and the female plants. However, further study is needed to support this statement in the local scenario.

\section{Conclusion}

Vegetative and reproductive traits are found to be the most important characteristics to differentiate the populations of $J$. indica that are influenced differently by the variation in elevation as the individuals at the lower-elevation were larger in vegetative size, with larger trunk, height, canopy area, and produced higher leaf biomass and greater number of fruits as compared to the individuals at the mid- and higher-elevations in this study. Trunk diameter, leaf dry-weight and fruits set parameters spatially varied within the same elevation class. The use of outer canopy area was also found to be the best option for non-destructively estimating the leaf biomass of $J$. indica. This technique can be, therefore, used for estimating the leaf biomass of J. indica for different purposes, e.g., for its bioenergy estimation as well as for quantification of its carbon stock.

\section{Acknowledgments}

We sincerely acknowledge the Missouri Botanical Garden (MBG), USA and the Central Department of Botany (CDB), Tribhuvan University, Nepal for their financial support to carry out this study. We are grateful to Dr. Jan Salick and Dr. Kattie Konchar, MBG, and Mr. Prem Subedi and Ms. Sita Karki, CDB for their suggestions and company during our fieldwork. We are highly thankful to two anonymous reviewers for their valuable comments and suggestions on the earlier version of the manuscript.

\section{References}

Adams, R. P. and Chaudhary, R. P. 1996. Leaf essential oil of Juniperus indica Bertol. from Nepal. Journal of Essential Oil Research 8: 677-680.

Adams, R. P., Thapa, R. K., Agrawal, S. G., Kapahi, B. K., Srivastava, T. N. and Chaudhary, R. P. 1998. The leaf essential oil of Juniperus recurva Buch. Ham. ex D. Don from India and Nepal compared with $J$. recurva var. squamata (D. Don) Parl. Journal of Essential Oil Research 10: 21-24.

Adams, R. P., Chaudhary, R. P., Pandey, R. N. and Singh, L. 2009. Juniperus recurva var. uncinata, the hooked branchlet juniper, a 
new variety from Nepal. Phytologia 91 (3): 361-366.

Ansley, R. J., Mirik, M., Surber, B. W. and Park, S. C. 2012. Canopy area and aboveground mass of individual redberry juniper (Juniperu spinchotii) trees. Society for Range Management 65 (2): 189-195.

Baniya, C. B., Solhøy, T. and Vetaas, O. R. 2009. Temporal changes in species diversity and composition in abandoned fields in a transHimalayan landscape, Nepal. Plant Ecology 201: 383-399.

Bhattarai, K. R., Vetaas, O. R. and Grytnes, J. A. 2004. Relationship between plant species richness and biomass in an arid sub-alpine grassland of the central Himalayas, Nepal. Folia Geobotanica 39: 57-71.

Bhattarai, S., Chaudhary, R. P. and Taylor, R. S. L. 2006. Ethnobotany of wild junipers (Juniperus species) in Manang district, Central Nepal. Scientific World 4 (4): 109112.

Ghimire, B. K., Lekhak, H. D., Chaudhary, R. P. and Vetaas, O. R. 2008a. Vegetation analysis along an altitudinal gradient of Juniperus indica forest in southern Manang Valley, Nepal. International Journal of Ecology and Development 9: 20-29.

Ghimire, S. K. and Devkota, B. 2008. NonTimber Forest Product (NTFP) Management Action Plan: Kumbhakarna Conservation Community Forest, Kanchenjunga Conservation Area, Lelep - 9, Ghunsa, Taplejung. WWF Nepal (in Nepali).

Ghimire, S. K., Sapkota I. B., Oli, B. R. and Parajuli, R. R. 2008b. Non-Timber Forest Products of Nepal Himalaya: Database of Some Important Species found in the Mountain Protected Areas and Surrounding Regions. WWF Nepal Program, Kathmandu, Nepal.

Gurung, K. 2010. Essential Oils Sector Study in Nepal: A Detailed Study of Anthopogon, Juniper and Wintergreen Essential Oils. GTZ, Lalitpur, Nepal.
Haymes, K. L. and Fox, G. A. 2012. Variation among individuals in cone production in Pinus palustris (Pinaceae). American Journal of Botany 99 (4): 640-645.

Juan, R., Pastor, J., Fernandez, I. and Diosdado, J. C. 2003. Relationships between cone traits and seed viability in Juniperus oxycedrus L. subsp. macrocarpa (Sm.) Ball (Cupressaceae). Acta Biologica Cracoviensia Series Botanica 45 (2): 69-78.

Klinka, K., Wang, Q., Carter, R. E. and Cher, H. Y. H. 1996. Height growth-elevation relationships in subalpine forests of interior British Columbia. The Forestry Chronicle 72 (2): 193-198.

KÖrner, C. and Chochrane, P. 1983. Influence of leaf physiognomy on leaf temperature on clear midsummer days in the Snowy Mountains, south-eastern Australia. Acta Oecologia 4: 117-124.

Ludwig, J. A., Reynolds, J. F. and Whitson, P. D. 1975. Size-biomass relationships of several Chihuahuan desert shrubs. The American Midland Naturalist 94: 451-461.

Mason, L. R. and Hutchings, S. S. 1967. Estimating foliage yields on Utah juniper from measurements of crown diameter. Journal of Range Management 20: 161-166.

Miehe, G., Winiger, M., Böhner, J. and Zhang, Y. 2001. The climate diagram map of High Asia: purpose and concepts. Erdkunde 55: 94-95.

Otárola, M. F., Sazima, M. and Solferini, V. N. 2013. Tree size and its relationship with flowering phenology and reproductive output in Wild Nutmeg trees. Ecology and Evolution 3 (10): 3536-3544.

Otto, R., Krüsi, B. O., Delgado, J. D., FernándezPalacios, J. M., García-Del-Rey, E. and Arévalo, J. R. 2010. Regeneration niche of the Canarian juniper: the role of adults, shrubs and environmental conditions. Annals of Forest Science 67 (7): 709.

Peek, J. M. 1970. Relation of canopy area and volume to production of three woody species. Ecology 51: 1098-1101. 
Press, J. R., Shrestha, K. K. and Sutton, D. A. 2000. Annotated Checklist of the Flowering Plants of Nepal. The Natural History Museum, London, UK.

Rastetter, E. B., Kwiatkowski, B. L, Dizes, S. L. and Hobbie, J. E. 2004. The role of down-slope water and nutrient fluxes in the response of arctic hill slopes to climate change. Biogeochemistry 69: 37-62.

Schemske, D. W., Husband, B. C., Ruckelshaus, M. H., Goodwillie, C., Parker, I. M. and Bishop, J. G. 1994. Evaluating approaches to the conservation of rare and endangered plants. Ecology 75: 584-606.

Subedi, P. U. 2016. Population Structure and Plant Performance of Juniperus squamata
Buch.-Ham. ex D. Don along an Elevation Gradient in Manang, Nepal. M.Sc. Thesis, Central Department of Botany, Tribhuvan University, Kritipur, Nepal.

Tackenberg, O. 2007. A new method for nondestructive measurement of biomass, growth rates, vertical biomass distribution and dry matter content based on digital image analysis. Annals of Botany 99: 777-783.

Vashum, K. T. and Jayakumar, S. 2012. Methods to estimate above-ground biomass and carbon stock in natural forests - A review. Journal of Ecosystem and Ecography 2: 4 http://dx.doi. org/10.4172/2157-7625.1000116 accessed on 27 December, 2016. 